\title{
The Application of "Flipped Classroom" in Vocal Music Teaching in Normal Colleges
}

\author{
Yingjuan Chi \\ Qilu Normal University
}

(Shangdong 250013)

\section{Keywords: Flipped classroom; Vocal music teaching; Teaching difference; Teaching mode}

\begin{abstract}
Based on the traditional teaching system formed in music schools, different teachings between schools produced making individual students unable to get targeted teaching, this is one of the reasons leading to the effectiveness of the vocal music teaching which is not high. The shortage and difference of the vocal music teaching of "flip the classroom" in the teaching concept, introduced to the practice of teaching in Colleges in order to change the traditional teaching patterns of the existing problems, and the vocal music teaching in Universities with continuous improvement to bring the students more perfect teaching to promote the development of the vocal music teaching mode.

With the comprehensive development and progress of our society, vocal music teaching has become an important content of education in art colleges. In this stage, the vocal music teaching is more and more important. In view of this problem, the proposed teaching mode-"flipped classroom" is analyzed according to the student individual problems teaching, adopting a more perfect vocal music teaching mode which has a positive impact on the development of vocal music teaching ideas. How can teachers use the "flipped classroom" in the vocal music teaching in normal colleges.
\end{abstract}

\section{The Problems of Vocal Music Teaching in Normal Colleges and the Feasibility of the Application of "Flipped Classroom" Teaching}

Main definition of "flip the classroom" The so-called "flipped classroom" is to create a video by the teacher, and the students in the classroom outside the independent arrangements for the time to watch the video from the teacher to explain a teaching form. Students spontaneously organized learning and setting up learning groups to encourage learning and mutual encouragement. The teachers will adopt the corresponding guiding methods through the students in the learning process. Students are beginning to realize that teachers are here only to guide their learning rather than to give instruction in class. The teacher plays the role of propagator of knowledge in the flipped classroom, and the purpose is to let the students know how to learn and how to combine the theory and practice.

Five advantages of "flip classroom". Teaching mode of "Flip the classroom" mainly has five advantages, the use of the advantages of information technology, video communication education, the traditional teaching one to many mode to one mode, to break the traditional classroom teaching methods to teach him to fish, and its aim is to cultivate students' according to the needs of creativity, the goal of learning-teaching mode will become more perfect, the students and teachers mutual learning and inquiry. Because of the characteristics and advantages of teaching video are dynamic, visual, integrated and interactive, and it can break the rigid pattern of traditional teaching to create and improve the traditional teaching and multimedia teaching, which means students can understand the point several times and can give consideration to each student's progress that is the traditional classroom can not reach.

Problems and challenges in vocal music teaching in normal colleges. Vocal music teaching is an important and direct way of music quality education, and the traditional teaching mode has been unable to meet the actual teaching needs. Influenced by the traditional vocal music teaching mode, the students can not make full use of the combination of theory and practice. At the same time, teachers seriously neglected fight the enemy separately, teaching objectives and teaching methods have formed their own 
characteristics in teaching which lead teachers do not pay attention to their own teaching quality improvement as the premise and not in accordance with the learning characteristics of the combination of theory and practice teaching. These problems are also the important reasons that leading to the improvement of vocal music teaching mode, and it is also a serious challenge in the current teaching mode.

Feasibility of the application of "flipped classroom" in vocal music teaching in Normal Colleges. Traditional vocal music teaching has been unable to meet the actual needs of College students. The application of the flipped classroom teaching mode plays an active role in teaching efficiency. Students can use the Internet to use high-quality educational resources no longer simply rely on the classroom teacher to teach knowledge only in the classroom. [1] At the same time, the classroom and the teacher's role has also undergone some changes. The teacher is more to solve the problems of students, guiding students to use knowledge to solve their own problems. This is conducive to enhance students' learning initiative, so that students' vocal music knowledge has been strengthened. This has a good development to build a good relationship between teachers and students. This kind of teaching mode can get rid of or permit professional skills in music college vocal music teaching mode of vocal music teaching mode to get rid of the shadow, and the teacher only isolated and helpless on"echo what the books say" teaching mode, which means the vocal music teaching in China can enhance new breakthrough. Therefore, the "flipped classroom" boldly used in vocal music teaching, and the reform of vocal music teaching in normal colleges will be an unprecedented change.

\section{"Flipped Classroom" in Vocal Music Teaching in Normal Colleges}

"Flipped classroom" in vocal music teaching in normal colleges. The "flipped classroom" is applied to the teaching model of professional music colleges, which has a good effect on the improvement of teachers' professional quality. "Flipped classroom" can not replace the traditional teaching thought, and it is a more perfect teaching mode. Through the network video voice teaching, it can strengthen communication and interaction between teachers and students and strengthen students' learning before class so as to reduce the content of the new students in learning before class pressure to enhance the efficiency of the classroom teaching plays a positive role. And help students after class can consolidate the contents of the review to achieve the perfect teaching. In the vocal music teaching, classroom activities should grasp the degree can create a good classroom atmosphere, but also to put in front of the classroom before the class corresponding to the problems in teaching which means with heavy and difficult problems such as a comprehensive presentation of this teaching method, students can be more clearly to strengthen collaborative learning between the students.

\section{Reflections on "flipped classroom" into the vocal music teaching in normal colleges}

How to achieve the "flipped classroom" into the vocal music teaching in normal colleges is the current controversy and problems. At present, the domestic level also failed to achieve the perfect situation, this can be transmitted to the students only after a simple video recording, and the main form is still not out of the PPT, while the form of talk is still not out of the text to explore the "flipped classroom" and widely application of the technology also has a long way to go. Therefore, this is a test of the quality of teachers themselves. In the course of classroom design, teachers should give full attention to the guidance of theory with fully reflecting the role of image data, according to the actual situation of students, it can improve the design of the whole course. At the same time, the flipped classroom video time should be controlled, and about 10-15 minutes in control with the content of the subject to be taught to achieve the purpose of education.

Implications of "flipped classroom" teaching mode for teachers. In a new vocal music teaching mode into the traditional vocal music teaching mode, "Flipped classroom" asks teachers occupy an important position. In the process of implementation in the flipped classroom teaching mode, and with teaching video quality, students can communicate each other, and whether the students to learn the time 
arrangement, the teachers in the classroom activities organized which all have an important impact on the effect of vocal teaching. Therefore, it is very important to enhance the quality of vocal music teachers, which is related to the improvement of the teaching of vocal music. Therefore, in the face of these problems, vocal music teachers in normal colleges should also think about their own problems to strengthen the professional.

\section{Construction and Cognition of the Vocal Music Course in the "Flipped Classroom" Teaching Mode}

Teaching platform of "flipped classroom" is the product of the information age. With the development of information technology, the digital classroom teaching mode appears. In order to fully digital resources to serve the students, applied to education, to maximize the use of the precious time in the classroom, and to further improve the independent learning and innovation ability of learners, "flipped classroom" has become one of the options. The teaching of "flipped classroom" is the product of the use of information technology, and it has its own pattern of diversification and novelty, which is different from the traditional vocal music teaching model. According to the characteristics of the information platform, teachers use network information technology to build a good learning platform for students. Although this is not consistent with the traditional teaching model, but the advantages of teaching is a comprehensive. In the face of excellent students with excellent vocal music, strengthening and enhancing the role in the face of vocal music is relatively weak students to alleviate the pressure of study, but also to learn vocal skills, and the vocal music teaching reform should highlight the demonstration which is completely consistent.

Concept of Vocal Music Teaching in the "Flipped Classroom". At present, China's vocal music in the flipped classroom teaching cognition is compared to fuzzy stage about how "flipped classroom" is widely used in vocal music teaching, and it is still a great challenge. In addition to the vocal music teachers in colleges to realize the importance of flipped classroom in education, but also the need for colleges and universities to give recognition in order to make the flip classroom which can be universally recognized. The teaching mode of "flipped classroom" is a kind of means to increase the interaction between students and teachers and to make the students improve their consciousness. [2] Teacher is no longer the classroom to bring pressure to the elders of the students by taking more interaction between students and teachers. Even if the students leave because of the absence of class, but it will not leave behind the course. The content of the course can be retained on the network, if necessary to watch learning, so that students leaving the missing courses can be filled to keep up with the pace of the overall.

Effect of "Flipped Classroom" in Vocal Music Teaching in Normal Colleges. The application of "flipped classroom" in music colleges, not only embodies the modern scientific and technological progress, and the convenience of the students before class and review after class to let the students focus on the learning of knowledge and skill to get a better understanding of it. This breaks the traditional classroom teaching mode, but also makes the students in time and space more freely making students' vocal learning quality has been greatly improved, and it also can let the student has been strengthened in the vocal skills learning.

\section{Conclusion}

In the vocal music teaching in normal colleges, the use of "flipped classroom" may be an effective way to change the defects of vocal music teaching in normal colleges in China. And along with the pace of the times, the Chinese vocal music teaching strategy has been improved. In fact, in the teaching mode as long as look for experience. No matter how the education reform, the maximum plays the main role with students, so that students should think about themselves if dare to show themselves, which is the 
"flipped classroom" reflected in the education of the biggest purpose. "flipped classroom" is not "overthrow", but a "turn", [3] With new ideas to educate students, giving full play to their own potential to promote students to better improve. The teaching mode of "flipped classroom" takes the dominant position of the students, and improves the students' learning pressure. Presumably, the future of vocal music teaching model will be more profound and more scientific changes because of the new teaching system.

\section{References}

[1] Shasha Li,American "flipped classroom" teaching mode[J],Educational Circles, 2014.

[2] Shanshan Chen,Some understanding of flipped classroom[J],New Curriculum·Middle School, 2015(12).

[3] Wei Tian, Qiuyan Li, Mingqian Wang, Study on flipped classroom teaching mode[J],Science Herald,2014. 